UPIA, Rheumatoid Arthritis (RA), Spondyloarthritis $(\mathrm{SpA})$ or Psoriatic Arthritis (PsA), respectively.

Results: During the follow-up 6 (14.3\%) UPIA reached a defined diagnosis (2 RA, $2 \mathrm{SpA}$ and 2 PsA, respectively). At baseline, UPIA who differentiated had higher GSUS $(p=0.01)$ and PDUS scores $(p=0.02)$ compared to patients who remained as UPIA within 1 year. At baseline, UPIA who differentiated towards defined arthritis had higher histological scores for lining and sublining $\operatorname{CD}^{+} 8^{+}(p=0.005$ and $p=0.04$ for lining and sublining, respectively), sublining $C D 3^{+}$cells $(p=0.002)$ and $C D 31^{+}$vessels count $(p<0.001)$ than patients who remained as UPIA. In addition, there were direct correlations between baseline GSUS and PDUS scores with lining $C D 68^{+}$cells scores $(p<0.001$ for GSUS and $p=0.02$ for PDUS scores respectively), sublining $C D 68^{+}$cells scores ( $p=0.02$ for GSUS and $p=0.03$ for PDUS scores respectively), sublining $\mathrm{CD}^{+}$cells score $(\mathrm{p}=0.002$ for GSUS and $p=0.002$ for PDUS scores respectively) and CD $31^{+}$vessels count $(p<0.001$ for GSUS and $\mathrm{p}=0.01$ for PDUS scores respectively) in UPIA. Finally, the areas under the receiver operating characteristic (ROC) curves $C D 31^{+}$vessels count (cut-off value: 24.3), GS score (cut-off value: 1.5) and PDUS score (cut-off value: 1.5) were calculated to assess the best cut-off points to identify the differentiation likelihood during the follow-up in UPIA patients. The logistic regression analysis, demonstrated that having baseline GSUS and PDUS scores $\geq 1.5$ [OR:13.64 (95\% Cl: 0.98-242.59); $\mathrm{p}=0.05]$ and $\mathrm{CD} 31^{+}$vessels count $\geq 24.3$ [OR:51.13 (95\% Cl: 3.15-829.16); $p=0.01]$ were independent factors associated with the achievement of defined arthritis.

Conclusions: Histological and US assessment may help in the identification of patients with seronegative UPIA with high likelihood of clinical differentiation towards defined arthritis.

Disclosure of Interest: None declared

DOI: 10.1136/annrheumdis-2017-eular.4841

\section{SAT0067 FURTHER TREATMENT INTENSIFICATIONS IN UNDIFFERENTIATED AND RHEUMATOID ARTHRITIS PATIENTS ALREADY IN LOW DISEASE ACTIVITY HAVE LIMITED BENEFIT TOWARDS PHYSICAL FUNCTIONING}

S.A. Bergstra ${ }^{1}$, O. Olivas ${ }^{2}$, G. Akdemir ${ }^{1}$, N. Riyazi ${ }^{3}$, G. Collee ${ }^{3}$, J.H. Van Groenendael $^{4}$, R.B. Landewé ${ }^{5,6}$, C.F. Allaart ${ }^{1} .{ }^{1}$ Rheumatology, LUMC, Leiden, Netherlands; ${ }^{2}$ Rheumatology, Hospital Universitario 12 de Octubre, Madrid, Spain; ${ }^{3}$ Medical Center Haaglanden, The Hague; ${ }^{4}$ Reumazorg Southwest Netherlands, Bergen op Zoom; ${ }^{5}$ Amsterdam Rheumatology \& Immunology Center, Amsterdam; ${ }^{6}$ Zuyderland Medical Center, Heerlen, Netherlands

Background: It is recommended to optimize treatment as long as a predefined treatment target is not met, but should we aim at remission if patients are in low disease activity (LDA)?

Objectives: To assess if RA or undifferentiated arthritis (UA) patients who achieved LDA benefit with better functional ability from treatment intensification aimed at DAS remission.

Methods: In the IMPROVED study 610 patients with early RA (ACR 2010) or UA were "treated to target" aimed at DAS remission, assessed 4-monthly. Initial treatment was methotrexate (MTX) + tapered high dose prednisone. Patients with DAS $\leq 1.6$ tapered treatment. Patients with DAS $>1.6$ were randomized to MTX + hydroxychloroquine + sulphasalazine + prednisone or to MTX + adalimumab. Over 5 years, patients with DAS $>1.6$ were required to increase, change or restart medication. HAQ was measured 4-monthly. A linear mixed model analysis with random intercept was performed to test the relationship between changes in therapy and HAQ over time. Patients in LDA with DAS $>1.6$ with and without (i.e. protocol violation) treatment change were compared. $\triangle \mathrm{HAQ}$ and $\triangle \mathrm{DAS}$ at each visit compared to the previous visit were calculated. We tested the interaction effect between change in treatment and follow-up time adjusted for possible confounders.

Results: Overall, over 5 years DAS (baseline mean (SD) 3.2 (1.7)) and HAQ (1.2 (0.7)) showed a statistically significant and clinically relevant decrease $(\triangle \mathrm{HAQ}$ $-0.59,95 \% \mathrm{Cl}-0.61,-0.57 ; \Delta \mathrm{DAS}-1.77,95 \% \mathrm{Cl}-1.79 ;-1.75)$. The number of patients in LDA per visit ranged from 88 to 146 , of which $26 \%$ to $73 \%$ (increasing over time) had no treatment change due to protocol violations. We found a statistically significant but not clinically relevant effect of treatment change on $\triangle \mathrm{HAQ}$, corrected for baseline $\mathrm{HAQ}$, age, gender and treatment arm (model 1 , $\beta-0.085,95 \% \mathrm{Cl}-0.13,-0.044$ ). When $\triangle \mathrm{DAS}$ was added (model 2), the effect of treatment change was partly explained by $\triangle \mathrm{DAS}$ and no longer statistically significant $(\beta-0.022,95 \% \mathrm{Cl}-0.060 ; 0.015)$. The effect of treatment intensification on HAQ improvement became less over time, as demonstrated by a statistically significant interaction between change in HAQ and time in follow-up in model 3 ( $\beta$ $0.0098,95 \% \mathrm{Cl} 0.0010 ; 0.019$ ) (table 1).

Conclusions: Treatment intensification in early RA or UA patients who have already achieved low disease activity is associated with a statistically significant decrease in HAQ, but not with a clinically meaningful improvement in functional ability. The effect on $\triangle \mathrm{HAQ}$ decreased with increasing follow-up time. Therefore not remission or low disease activity, but good functional ability may be the optimal treatment target at which to steer treatment adjustments. These results suggest that, whereas remission may be the optimal goal, when patients in low disease activity have acceptably low $\mathrm{HAQ}$, further treatment intensification may only have downsides such as side effects and costs.

Disclosure of Interest: None declared
Table 1: Linear Mixed Model analysis to assess the effect of treatment intensification on change in $\mathrm{HAQ}$.

\begin{tabular}{|c|c|c|c|}
\hline & $\beta$ & $\mathbf{P}$ & $95 \% \mathrm{~d}$ \\
\hline \multicolumn{4}{|l|}{ Model $1(n \text { patients }=479, n \text { visits }=1528)^{\circ}$} \\
\hline Treatment intensification & -0.085 & $<0 . \infty 1$ & $-0.13 ;-0.044$ \\
\hline Follow-up time & 0.0057 & 0.019 & $0.00094 ; 0.010$ \\
\hline \multicolumn{4}{|l|}{ Model 2 ( $n$ patients $=476, n$ visits $=1509)^{*}$} \\
\hline Treatment intensification & -0.022 & 0.246 & $-0.060 ; 0.016$ \\
\hline Follow-up time $e^{b}$ & 0.0022 & 0.313 & $-0.0021 ; 0.0066$ \\
\hline DAS change & 0.23 & $<0 . \infty 1$ & $0.21 ; 0.26$ \\
\hline \multicolumn{4}{|l|}{ Model $3(n \text { patients }=476, n \text { visits }=1509)^{\circ}$} \\
\hline Treatment intensification & -0.10 & 0.013 & $-0.18 ;-0.021$ \\
\hline Follow-up time & -0.0034 & 0.323 & $-0.010 ; 0.0033$ \\
\hline Treatment intensification " follow-up time & 0.0098 & 0.029 & $0.0010 ; 0.019$ \\
\hline DAS change & 0.23 & $<0.001$ & $0.21 ; 0.26$ \\
\hline
\end{tabular}

$\mathrm{HAQ}=$ health assessment questionnaire, $\mathrm{SE}=$ standard error, $\mathrm{Cl}=$ confidence interval.

-All models were adjusted for age, gender, treatment arm and baseline HAQ.

"Follow-up time is added to the model as visit number, with time between visits being

4 months

DOI: 10.1136/annrheumdis-2017-eular.1606

\section{SAT0068 THE TIME UNTIL PERFORMING TIGHT CONTROL AS A TREAT-TO-TARGET STRATEGY AND THE TOLERABILITY OF METHOTREXATE STRONGLY INFLUENCE THE ACHIEVEMENT OF CLINICAL REMISSION IN RHEUMATOID ARTHRITIS}

T. Hagiwara, K. Kamada, N. Namura. Rheumatology, Takarazuka City Hospital, Takarazuka, Japan

Background: Clinical remission (CR) is the first targeted outcome of early treatment for rheumatoid arthritis (RA). Therefore, a consensus is needed for achieving CR by using the treat-to-target (T2T) strategy in RA treatment. However, in patients who received long-term insufficient treatment for RA, achievement of CR becomes increasingly difficult, especially if there is delay in the treatment.

Objectives: We aimed to examine factors that hinder successful RA treatment. We believe that making primary-care physicians aware of treatment results will increase the remission rate of RA.

Methods: We examined 388 patients with RA who were observed between January and October 2016 and who had not received new disease-modifying anti-rheumatic drugs (DMARDs) more than 3 months before the observation day. We investigated their age at RA onset, sex, Steinbrocker radiographic stage and functional class, activity level, rheumatoid factor (RF), the anti-cyclic citrullinated peptide antibody and DMARDs prescribed at the first consultation (Prescribed Before), disease activity, status of methotrexate (MTX), glucocorticoids (GCs), and biologic agent use at the last observational day.

First, we analysed the assumed remissions by using the Boolean-based definition (Boolean remission) as a purpose variable for these factors. Furthermore, we examined the odds ratio (OR) and $95 \%$ confidence interval $(95 \% \mathrm{Cl}$ ) by using a multiple logistic regression analysis for the statistically significantly different factors.

As for the time-related factor, we recognized that each factor had distinct multiplex collinear characteristics. Therefore, we adopted the time required for the first consultation as disease duration with the most effective values as the analysis object. The representative factor for the functional assessment adopted class according to the number of effective analyses.

Results: We recognised the statistically significant differences in disease duration, stage, class at the time of the first medical examination, RF, Prescribed Before, and state of MTX and GCs use at the last observation day for the achievement of Boolean remission.

We examined the multiple logistic regression analysis with the previously mentioned results and obtained the following results.

- Disease duration (per 1 year); OR 1.110, 95\% Cl 1.048-1.175, $p<0.001$.

- MTX (state; using vs no using); OR 2.522, 95\% Cl 1.560-4.076, p $<0.001$

- Class at 1st interview; OR 1.512, 95\% Cl 1.126-2.029, $\mathrm{p}<0.01$

- GCs (state; no using vs using); OR 1.803, 95\% Cl 0.912-3.565, p=0.090.

- Disease duration ( $<1.605 y$ vs $>1.605 y)$; OR $2.233,95 \% \mathrm{Cl} 1.437-3.470$, $\mathrm{p}<0.001$.

- MTX (state; using vs no using); OR 2.656, 95\% CI 1.644-4.291, p $<0.001$

- Class at 1st interview; OR 1.589, 95\% Cl 1.181-2.136, $\mathrm{p}<0.01$.

- GCs (state; no using vs using); OR 1.883, 95\% Cl 0.956-3.711, p=0.067.

Conclusions: Our results indicated the importance of the time required for consultation facilities with the T2T strategy treatment, tolerability for MTX use, and mild dysfunction at the first interview.

The window of opportunity to achieve remission for patients with RA has less time than expected. Therefore, we recommend that physicians should introduce patients with RA to a rheumatologist following the T2T strategy promptly when the primary care provided by the family physician is insufficient. 
Disclosure of Interest: None declared

DOI: 10.1136/annrheumdis-2017-eular.2454

\section{SAT0069 A RAPID3-LIKE INDEX DOCUMENTS SUPERIOR EFFICACY OF BARICITINIB TO ADALIMUMAB AND PLACEBO, SIMILAR TO DAS28 AND CDAI IN THE RA-BEAM CLINICAL TRIAL IN PATIENTS WITH RHEUMATOID ARTHRITIS}

T. Pincus $^{1}$, B. Zhu ${ }^{2}$, C.J. Larmore ${ }^{2}$, J.D. Bradley ${ }^{2}$, N. Patel ${ }^{2}$, C.L. Gaich ${ }^{2}$, A.E. Koch ${ }^{2} .{ }^{1}$ Rush University Medical Center, Chicago; ${ }^{2}$ Eli Lilly and Company, Indianapolis, United States

Background: RAPID3 (Routine Assessment of Patient Index Data) indicates differences in efficacy of active versus control treatments at levels similar to DAS28-ESR (Disease Activity Score 28-Erythrocyte Sedimentation Rate) and CDAI (Clinical Disease Activity Index) in clinical trials of adalimumab, abatacept, certolizumab.

Objectives: To compare improvement according to RAPID3, DAS 28-ESR, and CDAl in the RA-BEAM trial of baricitinib vs adalimumab and placebo.

Methods: Post-hoc analyses were performed of the RA-BEAM trial, in which patients with moderately to severely active rheumatoid arthritis and an inadequate response to methotrexate (MTX) were randomized to baricitinib, adalimumab, or placebo. All patients were to continue stable background MTX and other DMARDs, as well as stable low-dose prednisone and/or NSAIDs, if indicated. A RAPID3-like index was computed from 3 measures: physical function (FN), pain (PN), and patient global assessment (PATGL). FN on a HAQ (Health Assessment Questionnaire) of 20 items [rather than MDHAQ (multidimensional HAQ) of 10 items] was recalculated from $0-3$ to $0-10 ; \mathrm{PN}$ and PATGL (visual analog scales) were recalculated from 0-100 to 0-10, for a 0-30 total score, hence "RAPID3-like". Mean values at baseline and Week 24 for RAPID3-like, DAS28-ESR, and CDAI, and percent change from baseline were computed in the 3 treatment groups. The proportion of patients with high/moderate activity/severity at Week 24 versus low activity/severity/remission, as well as correlations of the 3 indices at Week 24, were calculated. Statistical significance for percent change was analyzed using Wilcoxon tests, after imputation of missing values using modified last observation carried forward (mLOCF); low activity/severity/remission was compared between groups using a logistic model, adjusting for region and baseline joint erosion status after imputation of missing values using non-responder imputation.

Results: Improvement from baseline to Week 24 ranged from $19.2 \%$ to $37.0 \%$ in placebo patients, $40.0 \%$ to $65.9 \%$ in baricitinib-treated patients, and $37.6 \%$ to $60.9 \%$ in adalimumab-treated patients (Table), least in DAS28-ESR, intermediate in RAPID3-like, and highest in CDAI. Changes according to RAPID3-like, DAS28ESR and CDAI were similar in the 3 treatment groups; baricitinib and adalimumab were superior to placebo according to all indices, and baricitinib was superior to adalimumab according to RAPID3-like and CDAI (Table). Correlations of RAPID3like with DAS28-ESR and CDAl ranged from $r=0.61$ to 0.75 and for DAS28-ESR with CDAl from $r=0.86$ to 0.91 (all $p<0.001$ ). The proportion of patients with low activity/severity/remission at Week 24 ranged from $9.6 \%$ to $19.7 \%$ in placebo patients, $31.6 \%$ to $49.9 \%$ in baricitinib-treated patients, and $33.6 \%$ to $47.6 \%$ in adalimumab-treated patients. RAPID3-like results were intermediate between DAS28-ESR and CDAI.

\begin{tabular}{|c|c|c|c|c|c|c|c|c|}
\hline & & \multirow[b]{2}{*}{$\begin{array}{c}\text { Baseline } \\
\text { Mean }\end{array}$} & \multirow[b]{2}{*}{$\begin{array}{c}\text { Week } 24 \\
\text { Mean }\end{array}$} & \multirow{2}{*}{$\begin{array}{c}\text { Week } 24 \\
\% \text { Change } \\
\text { from Baseline }\end{array}$} & \multirow[b]{2}{*}{$\begin{array}{l}\text { Correlation with } \\
\text { DAS28.ESR }\end{array}$} & \multirow[b]{2}{*}{$\begin{array}{l}\text { Correlation } \\
\text { with CDAI }\end{array}$} & \multirow{2}{*}{$\begin{array}{c}\text { High or Mod } \\
\text { at Week } 24 \\
\text { n (\%) }\end{array}$} & \multirow{2}{*}{$\begin{array}{c}\text { Low or } \\
\text { Remission } \\
\text { at Week } 24 \\
n(\%)\end{array}$} \\
\hline & & & & & & & & \\
\hline \multirow[t]{4}{*}{ RAPID3-like } & $\begin{array}{l}\text { Placebo } \\
(\mathrm{N}=488)\end{array}$ & 17.2 & 12.7 & $-22.5 \%$ & 0.69 & 0.61 & $399(81.8 \%)$ & $89(18.2 \%)$ \\
\hline & $\begin{array}{l}\text { Baricitinib } \\
(\mathrm{N}=487)\end{array}$ & 17.7 & 8.4 & $-51.0 \% \cdots " \neq \neq$ & 0.67 & 0.63 & $266(54.6 \%)$ & $221(45.4 \%)^{w^{*} \neq \neq} \neq$ \\
\hline & $\begin{array}{l}\text { Adalimumab } \\
(\mathrm{N}=330)\end{array}$ & 17.8 & 9.6 & $-45.6 \%^{* \cdots}$ & 0.75 & 0.70 & $217(65.8 \%)$ & $113(34.2 \%)^{* * *}$ \\
\hline & $\begin{array}{l}\text { All } \\
(N=1305)\end{array}$ & & & & 0.73 & 0.67 & & \\
\hline \multirow[t]{4}{*}{ DAS28-ESR } & $\begin{array}{l}\text { Placebo } \\
(\mathrm{N}=488)\end{array}$ & 6.4 & 5.2 & $-19.2 \%$ & N/A & 0.91 & $441(90.4 \%)$ & $47(9.6 \%)$ \\
\hline & $\begin{array}{l}\text { Baricitinib } \\
(\mathrm{N}=487)\end{array}$ & 6.5 & 3.9 & $-40.0 \% \cdots$ & N/A & 0.86 & $333(68.4 \%)$ & $154(31.6 \%)^{m m}$ \\
\hline & $\begin{array}{l}\text { Adalimumab } \\
(\mathrm{N}=330)\end{array}$ & 6.4 & 4.0 & $-37.6 \% \cdots$ & N/A & 0.87 & $219(66.4 \%)$ & $111(33.6 \%)^{* *}$ \\
\hline & $\begin{array}{l}\text { All } \\
(N=1305)\end{array}$ & & & & N/A & 0.90 & & \\
\hline \multirow[t]{4}{*}{$\overline{\mathrm{CDAI}}$} & $\begin{array}{l}\text { Placebo } \\
(\mathrm{N}=488)\end{array}$ & 37.6 & 23.4 & $-37.0 \%$ & 0.91 & N/A & $392(80.3 \%)$ & $96(19.7 \%)$ \\
\hline & $\begin{array}{l}\text { Baricitinib } \\
(\mathrm{N}=487)\end{array}$ & 38.1 & 13.0 & $-65.9 \% \cdots+\cdots$ & 0.86 & N/A & $244(50.1 \%)$ & $243(49.9 \%)^{* \cdots}$ \\
\hline & $\begin{array}{l}\text { Adalimumab } \\
(\mathrm{N}=330)\end{array}$ & 38.0 & 15.0 & $-60.9 \% \cdots$ & 0.87 & N/A & $173(52.4 \%)$ & $157(47.6 \%)^{1 * *}$ \\
\hline & $\begin{array}{l}\text { All } \\
(N=1305)\end{array}$ & & & & 0.90 & N/A & & \\
\hline
\end{tabular}

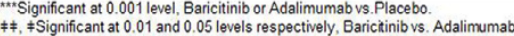

Abbreviations: $C D A=$ Alinical Disease Activity Index; DAS28-ESR=Disease Activity Score 28-erythrocye sedimentation rate $\mathrm{H}$ High=high disease actinity/severity; Low=low disease activity/severity: Mod=moderate
$\mathrm{N}=$ number of patients: RAPID3-like=Routine Assessment of Patient Index Data 3-like.

Conclusions: RAPID3-like documented greater efficacy of baricitinib versus adalimumab and placebo in the RA-BEAM trial, with results in similar ranges to DAS28-ESR and CDAI. RAPID3 is feasible to provide quantitative, standard medical history data; almost of the time and effort is by the patient rather than a health professional, assuring quantitative data in the infrastructure of usual clinical care.
Disclosure of Interest: T. Pincus Shareholder of: Health Report Services, B. Zhu Employee of: Eli Lilly and Company, C. Larmore Employee of: Eli Lilly and Company, J. Bradley Employee of: Eli Lilly and Company, N. Patel Employee of: Eli Lilly and Company, C. Gaich Employee of: Eli Lilly and Company, A. Koch Employee of: Eli Lilly and Company

DOI: 10.1136/annrheumdis-2017-eular.1813

\section{SAT0070 BARICITINIB VERSUS ADALIMUMAB IN PATIENTS WITH ACTIVE RHEUMATOID ARTHRITIS: ANALYSIS OF PATIENTS ACHIEVING A MODERATE EULAR RESPONSE AT WEEK 4}

T.K. Kvien $^{1}$, P. van Riel ${ }^{2}$, A. Rubbert-Roth ${ }^{3}$, R. Blanco ${ }^{4}$, S.S. Liu-Leage ${ }^{5}$, E. Larsson ${ }^{5}$, H. Lund ${ }^{5}$, P. López-Romero ${ }^{5}$, L. Zaremba-Pechmann ${ }^{5}$, P. Emery ${ }^{6}$. ${ }^{1}$ Diakonhjemmet Hospital, Oslo, Norway; ${ }^{2}$ Bernhoven, Uden, Netherlands; ${ }^{3}$ Uniklinik Köln, Köln, Germany; ${ }^{4}$ Hospital Universitario Valdecilla, Santander, Cantabria, Spain; ${ }^{5}$ Eli Lilly and Company, Indianapolis, United States; ${ }^{6}$ Leeds MSK Biomed/Chapel Allerton Hosp, Leeds, United Kingdom

Background: Baricitinib (BARI) is a selective inhibitor of Janus kinase, ${ }^{1}$ improves disease activity in patients (pts) with rheumatoid arthritis (RA), and is associated with inhibition of structural joint damage. ${ }^{2-4}$ Response to BARI observed at week (wk) 4 may be useful to predict future response..$^{5}$

Objectives: To characterise pts with RA who achieved moderate EULAR responses (MERs) ${ }^{6}$ at wk 4 and to describe the outcomes through wk 52 while continuing the assigned treatment.

Methods: Pts enrolled in the RA-BEAM study with active RA who had an inadequate response to methotrexate (MTX) were randomised 3:3:2 to placebo (PBO), BARI $4 \mathrm{mg}$ once daily, or adalimumab (ADA) $40 \mathrm{mg}$ biweekly. ${ }^{1}$ Pts who showed good or no EULAR responses at wk 4 were excluded. For the MER cohort, the cumulative incidence for first transition to good EULAR response and to no EULAR response from wk 4 through wk 52 was estimated in the presence of competing risks events, which either hinder observation of the events of interest or modify the chance that these events occur. ${ }^{7}$ Pts who transitioned from MER to no EULAR response or pts who were rescued or discontinued because of an adverse event or lack of efficacy were counted as no EULAR response; pts who discontinued the study for other reasons (eg, lost to follow-up, death) were censored at the time of discontinuation. No formal statistical tests were performed for these post hoc analyses.

Results: Of 1305 pts who received at least 1 dose of study drug, 683 experienced MERs at wk 4, including 37.3\% (182/488), 62.0\% (302/487), and 60.3\% (199/330) of pts on PBO, BARI, and ADA, respectively. Pts who achieved MERs at wk 4 on $B A R I$ and ADA had similar baseline disease activity characteristics (Table 1). The mean age of the MER subgroup was 53 years, and the mean disease duration was 8.7 years. The mean MTX dosage was $15 \mathrm{mg} / \mathrm{wk}$, and $59 \%$ of pts were taking concomitant oral glucocorticoids. At wk 4, 27\% (131/487) and $11 \%(54 / 487)$ of pts on BARI vs $29 \%(95 / 330)$ and $11 \%(36 / 330)$ of pts on ADA experienced no response or good response, respectively. The cumulative incidence for the first transitions to good EULAR response at wks 12, 24, and 52 was higher in pts who reached MERs at wk 4 on BARI than those on ADA. The cumulative incidence for the first transitions to subsequent no EULAR response was higher in pts who achieved MER at wk 4 on ADA (Figures $1 A$ and 1B, Table 2) than those on BARI. Conclusions: Among pts achieving early MER on BARI and ADA, subsequent loss of response was less common for pts on BARI than for those on ADA. Transitions to good EULAR response were more common for pts who achieved MERs on BARI than for those on ADA. Mechanistic explanations warrant future study.

\begin{tabular}{|c|c|c|c|c|c|c|}
\hline \multicolumn{3}{|c|}{ Characteristic } & \multicolumn{2}{|c|}{$\begin{array}{c}\text { Baricitinib } \\
n=302^{*}\end{array}$} & \multicolumn{2}{|c|}{$\begin{array}{c}\text { Adalimumab } \\
n=199^{*}\end{array}$} \\
\hline \multicolumn{3}{|c|}{$\begin{array}{l}\text { Background therapy } \\
\text { (MTX only), no. (\%) }\end{array}$} & \multicolumn{2}{|c|}{$259(85.8)$} & \multicolumn{2}{|c|}{$173(86.9)$} \\
\hline \multicolumn{3}{|c|}{$\begin{array}{l}\text { Background therapy } \\
\text { (MTX + other cDMARD), no. (\%) }\end{array}$} & \multicolumn{2}{|c|}{$43(14.2)$} & \multicolumn{2}{|c|}{$26(13.1)$} \\
\hline \multirow{2}{*}{\multicolumn{7}{|c|}{ DAS28-ESR category, no. (\%) }} \\
\hline & & & & & & \\
\hline \multicolumn{3}{|l|}{$>3.2$ to $\leq 5.1$} & \multicolumn{2}{|c|}{$12(4.0)$} & \multicolumn{2}{|c|}{$8(4.0)$} \\
\hline & \multicolumn{2}{|c|}{$290(96.0)$} & \multicolumn{2}{|c|}{$191(96.0)$} \\
\hline \multirow{2}{*}{\multicolumn{3}{|c|}{$\begin{array}{l}\text { Baseline mTSS, mean(SD) } \\
\text { HAQ-DI total score, mean (SD) }\end{array}$}} & \multirow{2}{*}{\multicolumn{2}{|c|}{$\begin{array}{l}42.0(50.0) \\
1.6(0.7)\end{array}$}} & \multicolumn{2}{|c|}{$47.1(51.9)$} \\
\hline & & & & & & \\
\hline \multicolumn{7}{|c|}{$\begin{array}{l}\text { Abbreviations: CDIMARD=conventional disease-modifying antirheumatic drug; DAS28-ESR=Disease } \\
\text { Activity Score modified to include the } 28 \text {-joint count based on the erythrocyte sedimentation rate; } \\
\text { HAQ-DI=Health Assessment Questionnaire-Disability Index; mTSS=modified Total Sharp Score; } \\
\text { WTX=methotrexate. } \\
\text { ₹501 patients reached moderate EULAR response at week } 4: 302 / 487(62 \%) \text { and } 199 / 330(60 \%) \text { for } \\
\text { BARI and ADA, respectively. }\end{array}$} \\
\hline \multicolumn{7}{|c|}{ Table 2: Time to First Transitionto Good and to No EULAR Response (DAS28-ESR) } \\
\hline & \multicolumn{3}{|c|}{ Baricitinib } & \multicolumn{3}{|c|}{ Adalimumab } \\
\hline & $\begin{array}{c}\begin{array}{c}\text { Cumulative } \\
\text { Incidence } \\
(\%)\end{array} \\
\end{array}$ & \multicolumn{2}{|c|}{ Lower ${ }^{95 \%} \mathrm{Cl}$ Upper } & $\begin{array}{c}\text { Cumulative } \\
\text { Incidence } \\
(\%)\end{array}$ & \multicolumn{2}{|c|}{$95 \% \mathrm{Cl}$} \\
\hline \multicolumn{7}{|c|}{ Transition to GoodResponse } \\
\hline Week12 & 18.3 & 14.1 & 22.8 & 15.2 & 10.6 & 20.5 \\
\hline Week 24 & 49.2 & 43.4 & 54.7 & 42.9 & 35.9 & 49.7 \\
\hline Week 52 & 63.6 & 57.8 & 68.8 & 58.1 & 50.9 & 64.7 \\
\hline \multicolumn{7}{|c|}{ Transition to No Response } \\
\hline Week12 & 8.6 & 5.8 & 12.2 & 13.2 & 8.9 & 18.3 \\
\hline Week 24 & 18.9 & 14.7 & 23.5 & 25.5 & 19.6 & 31.7 \\
\hline Week 52 & 24.2 & 19.5 & 29.2 & 28.9 & 22.7 & 35.4 \\
\hline
\end{tabular}

28-joint count based on the erythrocyte sedimentation rate. 